\title{
The Undergraduate ALFALFA Team: A Collaborative Model for Undergraduate Research in Major Long-term Astronomy Projects
}

\begin{abstract}
The research landscape in many areas of science has migrated toward increasingly large collaborations with the work done over long time periods, making it ever more challenging to involve undergraduates in cutting-edge projects. We describe our 19-institution collaboration founded to promote undergraduate research and faculty development within the context of an astronomical-survey project, discuss its efficacy, and summarize how this model may be applied to other large-scale research projects.
\end{abstract}

\section{Introduction}

Astronomy is experiencing a revolution in the wealth of data provided by modern satellites, new telescope technology, gravity wave interferometers, high-performance computers, and large "legacy" surveys of the sky.* This has led to the discovery of thousands of extra-solar planets, the presence of water on Mars, and explosions so powerful they give out more energy in a second than the sun gives out over its entire lifetime. We have learned that the universe is expanding faster and faster as time passes and, amazingly, we have determined precise details about the conditions of the universe when it was only 0.003 percent of its current age.

Several ongoing major astronomical surveys have produced data for millions of galaxies (e.g., York et al. 2000), stretched over distances so vast that the light from some of the farthest has traveled for billions of years to reach our telescopes. The planning and development of the next generation of telescopes (Astro2010 Committee 2010) indicates that the coming decades will bring even greater discoveries. It is truly an exciting time for astronomers and those students, graduate and undergraduate, contemplating a career in astronomy, physics, or other STEM (science, technology, engineering, and mathematics) disciplines.

Despite a common desire in many children and younger people to explore the natural sciences, something about the experience of studying science in our schools seems to alienate them, and the performance of middle school and high school students in science and mathematics education in the United States has lagged behind the top international performers (Martin et al. 2012; Mullis et al. 2009). A few high-achieving undergraduate students retain their fascina- tion for the natural sciences and do manage to get involved in scientific research, but often not until their last year of college. As CUR has emphasized, however, the undergraduate research experience is a high-impact pedagogical practice that should be available to as broad a range of students as possible (Kuh 2008; Rowlett, Blockus, and Larson 2012).

A particular challenge, then, is how to attract and engage students in the sciences early in their college careers and provide them with an accessible, yet challenging and intellectually satisfying, experience in scientific research. In the context of large, long-term projects, an additional challenge is how to involve them in the project as a whole, so that they can see the scope of the project rather than being limited to small technical side projects. Here we present one example of how the major ALFALFA survey has been designed to involve meaningful participation by undergraduates.

\section{The ALFALFA Survey Project}

The Arecibo Legacy Fast ALFA (ALFALFA) survey (Giovanelli et al. 2005) was designed to examine clouds of atomic hydrogen gas in galaxies outside our own, revealing the raw material out of which stars form and allowing us to trace the presence of dark matter. The survey covered an area of sky equivalent to 28,000 moons and used the Arecibo 305-m radio telescope at the National Astronomy and Ionosphere Center (NAIC), located near Arecibo, Puerto Rico. This telescope is the world's largest single aperture radio telescope (about the size of 26 football fields). Incorporating new technology such as the Arecibo L-band Feed Array (ALFA) receiver (the first multi-pixel radio camera to be used in conjunction with the size and power of the Arecibo dish) allowed ALFALFA team members to conduct an enormous survey in just seven years that otherwise would have taken fifty years to complete. The ALFALFA Team is a group of faculty and students from a diverse set of 19 institutions (see Table 1).

The contribution made by ALFALFA scientists to our understanding of the local universe is undeniable. It is the largest and most sensitive survey of cool atomic hydrogen in external galaxies ever performed, and it has probed more deeply than any previous surveys, to distances of 800 million light years. It has eight times the ability to see faint galaxies, compared to previous surveys (Giovanelli et al. 2005). It is also 
the first survey to cover enough of the overall sky to locate a significant sample of relatively rare, very massive galaxies simultaneously with hard-to-detect faint dwarf galaxies. In effect, it is the first "cosmologically significant" survey of hydrogen-bearing galaxies ever conducted. Thus far, the payoff has been substantial, producing more than 84 refereed journal articles by scientists participating in the survey. The ALFALFA survey is truly "big science."

\section{The Undergraduate ALFALFA Team}

From the outset of ALFALFA, the leaders of the project, Riccardo Giovanelli and Martha Haynes at Cornell University, sought to open the project to undergraduate participation. The Undergraduate ALFALFA Team (UAT) was conceived in 2004 by a small group of faculty members from several New York and Pennsylvania undergraduate liberal arts institutions, plus the University of Puerto Rico. One-day workshops were hosted at Union College in Schenectady, New York, which introduced attendees to ALFALFA and the possibility of working on related research while maintaining positions at primarily small, somewhat isolated undergraduate institutions.

The undergraduate team obtained funding from the National Science Foundation from 2007 to 2012 through a three-institution collaborative grant to Union College (principal investigator Rebecca A. Koopmann), Colgate University (principal investigator Thomas Balonek), and Georgia Southern University (principal investigator Sarah Higdon). The team then included 14 institutions across the United States and Puerto Rico. In its second phase of funding, between 2012 and 2016 through funding to Koopmann, the UAT expanded to 19 institutions: ten private colleges and universities, six public universities, and three research institutions (see Table 1).

Careful thought was given to the challenges of connecting isolated researchers in small-college environments, yet effectively involving their undergraduates in a large research collaboration. The team identified several priorities: (1) communicating a basic understanding of radio astronomy and extragalactic astrophysics to students with little or no class preparation, (2) providing resources for faculty and students to obtain computers and travel funds to support research, (3) identification of undergraduate-appropriate research projects, and (4) demonstration of modern collaborative science.

The cornerstone of the UAT is an annual workshop, which has been held every January between 2008 and 2015 at the Arecibo Observatory in Puerto Rico. There is no better way to instill enthusiasm for radio astronomy than to send students to the Arecibo Observatory. The workshop provides an overview of the ALFALFA scientific work, as well as training in research methods, as it nurtures peer and mentor collaboration. Teams of undergraduates and faculty members engage in active group projects (known as "scavenger hunts"), overnight observing using the Arecibo telescope, hands-on data analysis, and presentations of results.

\section{Table 1. Undergraduate ALFALFA Team Institutions and Faculty Leads}

\begin{tabular}{|l|l|l|}
\hline Institution & Location & Team Lead \\
\hline $\begin{array}{l}\text { Chicago State } \\
\text { University }\end{array}$ & Chicago, IL & Kimberly Coble \\
\hline Colgate University & Hamilton, NY & Thomas Balonek \\
\hline Cornell University & Ithaca, NY & Martha Haynes \\
\hline $\begin{array}{l}\text { George Mason } \\
\text { University }\end{array}$ & Fairfax, VA & Jessica Rosenberg \\
\hline $\begin{array}{l}\text { Georgia Southern } \\
\text { University }\end{array}$ & Statesboro, GA & Sarah Higdon \\
\hline Hartwick College & Oneonta, NY & Parker Troischt \\
\hline Ithaca College & Ithaca, NY & David Kornreich \\
\hline Lafayette College & Easton, PA & G. Lyle Hoffman \\
\hline Macalester College & St. Paul, MN & John Cannon \\
\hline $\begin{array}{l}\text { St. Lawrence } \\
\text { University }\end{array}$ & Canton, NY & Aileen O'Donoghue \\
\hline $\begin{array}{l}\text { St. Mary's College } \\
\text { of CA }\end{array}$ & Moraga, CA & Ron Olowin \\
\hline Siena College & Loudonville, NY & Rose Finn \\
\hline Skidmore College & Saratoga Springs, NY & Mary Crone Odekon \\
\hline Union College & Schenectady, NY & Rebecca Koopmann \\
\hline $\begin{array}{l}\text { University of Puerto } \\
\text { Rico }\end{array}$ & San Juan, PR & Mayra Lebron Santos \\
\hline $\begin{array}{l}\text { University of San } \\
\text { Francisco }\end{array}$ & San Francisco, CA & Aparna Venkatesan \\
\hline $\begin{array}{l}\text { University of } \\
\text { Wisconsin Madison } \\
\text { Point }\end{array}$ & Madison, WI & Eric Wilcots \\
\hline $\begin{array}{l}\text { West Texas A\&M } \\
\text { University of }\end{array}$ & Stevens Point, WI & Adriana Durbula \\
\hline
\end{tabular}

In fact, however, the activities actually begin in the months preceding the workshop, with student teleconferences designed to introduce background material and scientific motivation. The immersive workshop experience encourages students to then pursue ALFALFA research projects on their home campuses, and, in fact, 80 percent of participants have gone on to complete at least one independent research project using UAT research funds or institutional resources. The UAT faculty members are also reinvigorated by the project; the workshop provides a huge boost of energy and sense of community. 
Table 2. Sample of Recent UAT Student Academic Year (AY) and Summer Research Projects

\begin{tabular}{|c|c|c|}
\hline Institution & Project Tiłles (\# of Students) & Year(s) \\
\hline $\begin{array}{l}\text { Chicago State } \\
\text { University }\end{array}$ & $\begin{array}{l}\text { Analyzing } \mathrm{H} \alpha \text { Observations of MKW10 (1) } \\
\mathrm{HI} \text { Gas Properties of MKW10 (2) }\end{array}$ & $\begin{array}{l}2015 \text { Summer } \\
2014 \text { Summer }\end{array}$ \\
\hline Cornell University & $\begin{array}{l}\text { Finding Low Mass Galaxies in ALFALFA and SDSS } \\
\text { (1) } \\
\text { Discovering Void Galaxies in the Pisces-Perseus } \\
\text { Region (1) }\end{array}$ & $\begin{array}{l}\text { 2014-15 AY } \\
2014 \text { Summer }\end{array}$ \\
\hline Hartwick College & $\begin{array}{l}\text { Constructing PYTHON Codes for ALFALFA Data } \\
\text { Analysis (1) } \\
\text { Star Formation and Gas Content in the NRGb } 168 \\
\text { and NRGb } 301 \text { Galaxy Groups (2) }\end{array}$ & $\begin{array}{l}\text { 2015-16 AY } \\
2013 \text { Summer }\end{array}$ \\
\hline Lafayette College & $\begin{array}{l}\text { Effects of Environment on Galaxies Around HCG } \\
069 \text { (1) } \\
\text { Angular Momentum of ALFALFA Galaxies (1) }\end{array}$ & $\begin{array}{l}2015 \text { Summer } \\
2015 \text { Summer }\end{array}$ \\
\hline Macalester College & $\begin{array}{l}\text { Almost Dark Galaxies (1) } \\
\text { The Role of Cold Gas in Low-Level Supermassive } \\
\text { Black Hole Activity (1) }\end{array}$ & $\begin{array}{l}\text { 2014-15 AY } \\
2014-15 \mathrm{AY}\end{array}$ \\
\hline $\begin{array}{l}\text { St. Lawrence } \\
\text { University }\end{array}$ & $\begin{array}{l}\text { Reduction and Analysis of L-Band Wide Observations } \\
\text { of Galaxies in the Pisces-Perseus Void (1) }\end{array}$ & 2015 Summer \\
\hline $\begin{array}{l}\text { St. Mary's College } \\
\text { of CA }\end{array}$ & $\begin{array}{l}\text { Reduction of Targeted HI Observations of the } \\
\text { Pisces-Perseus Supercluster (3) } \\
\text { Analyzing the Poor Galaxy Cluster AWM3 (2) }\end{array}$ & $\begin{array}{l}2015 \text { Summer } \\
2014 \text { Summer }\end{array}$ \\
\hline Siena College & $\begin{array}{l}\text { Analysis of } \mathrm{H} \alpha \text { Imaging from Kitt Peak National } \\
\text { Observatory (1) } \\
\text { Star Formation in the MKW } 11 \text { Group of Galaxies } \\
\text { (4) }\end{array}$ & $\begin{array}{l}\text { 2014-15 AY } \\
2014 \text { Summer }\end{array}$ \\
\hline Skidmore College & $\begin{array}{l}\mathrm{HI} \text { in Filament and Group Environments (4) } \\
\text { Are Galaxies Pre-Processed in Filaments? (5) }\end{array}$ & $\begin{array}{l}\text { 2014-15 AY } \\
2015 \text { Summer }\end{array}$ \\
\hline Union College & $\begin{array}{l}\text { The Quenching of Star Formation in the Group } \\
\text { Environment (1) } \\
\text { Elimination of RFI in Spectral Data (1) }\end{array}$ & $\begin{array}{l}\text { 2014-15 AY } \\
2015 \text { Summer }\end{array}$ \\
\hline $\begin{array}{l}\text { University of Puerto } \\
\text { Rico }\end{array}$ & A WISE View of Almost Dark Galaxies (3) & 2013-14 AY \\
\hline $\begin{array}{l}\text { University of San } \\
\text { Francisco }\end{array}$ & $\begin{array}{l}\text { The Escape of First Light From Early Galaxies (1) } \\
\text { Constraints from Local Dwarf Galaxies and Low-mass } \\
\text { ALFALFA Galaxies on the First Stars (1) }\end{array}$ & $\begin{array}{l}\text { 2014-15 AY } \\
2013 \text { Summer }\end{array}$ \\
\hline $\begin{array}{l}\text { University of } \\
\text { Wisconsin Madison }\end{array}$ & $\begin{array}{l}\text { Star Formation and Stellar Population in ALFALFA } \\
\text { Galaxy Groups (1) } \\
\text { Refining Current Algorithms for Defining Galaxy } \\
\text { Groups (1) }\end{array}$ & $\begin{array}{l}\text { 2014-15 AY } \\
2014-15 \mathrm{AY}\end{array}$ \\
\hline $\begin{array}{l}\text { University of } \\
\text { Wisconsin Stevens } \\
\text { Point }\end{array}$ & $\mathrm{H} \alpha$ Calibration of MOSAIC Images (1) & 2012-13 AY \\
\hline West Texas A\&M & $\begin{array}{l}\text { Star Formation Properties of Galaxies in the } \\
\text { Zwicky 1400+09 Poor Cluster (1) } \\
\text { Connecting Astronomical Databases with Galaxy } \\
\text { Group Images (1) }\end{array}$ & $\begin{array}{l}\text { 2014-15 AY } \\
2014 \text { Summer }\end{array}$ \\
\hline
\end{tabular}

Beyond the January workshop, on-site observing sessions provide additional opportunities for students to visit the Arecibo Observatory. Coordination with schedulers allows observing runs during Thanksgiving and spring breaks so that faculty and students miss no classes. Aside from the wow factor, the trips are intensive training opportunities in which undergraduates learn how to operate the largest radio telescope in the world. As one student remarked, "This is the coolest thing I've ever done."

Since the conclusion of the ALFALFA survey in 2012, UAT faculty have collaborated with ALFALFA principal investigators to write their own proposals to perform targeted follow-up observations, both at the workshops and during the on-site observing runs each semester, to identify and characterize the most exciting ALFALFA sources (for example, galaxies with plenty of gas, but few or no stars, and super-powerful microwave laser candidates formed during galactic collisions). Once faculty members have on-site observing experience, they can conduct additional observing runs remotely from laboratories and classrooms at their home institutions, allowing more students on campus to participate.

During summers and throughout the academic year, faculty mentors supervise undergraduates on intellectually engaging research projects associated with the ALFALFA survey. Funds to purchase computers dedicated to ALFALFA research have facilitated these projects, particularly at institutions unable to provide research computers for their faculty. Over the 20142015 year alone, 29 academic-year and 28 summer research projects were conducted by UAT participants. The projects covered a range of topics, relying on the expertise and interest of each faculty member. Examples are "An $\mathrm{H} \alpha$ Survey of Star Formation in Undergraduate ALFALFA Team Groups and Clusters" (University of Wisconsin-Stevens Point); "Almost Dark Galaxies" (Macalester College); and "Improving and Completing Data Analysis of Star Formation in Group Galaxies with Python Programming" (Union College). A sample of some more recent summer and academic year under- 
graduate research projects is shown in Table 2 (of the total of 280 research projects). Summer students make presentations to the UAT collaboration through an annual summer teleconference (in addition to the presentations at conferences mentioned below).

For many students, the culmination of their research is the opportunity to present at national meetings such as those of the American Astronomical Society (AAS). Fifty-nine students have presented first-author posters at the AAS, with many others participating as coauthors or presenting at other meetings, including those of the American Physical Society, the National Society of Black Physicists, the Astronomical Society of New York, and Conferences for Undergraduate Women in Physics. Almost all student researchers have presented at on-campus venues. Some have been coauthors on collaborative papers published in The Astronomical Journal or The Astrophysical Journal (e.g. Cannon et al. 2011; BernsteinCooper et al. 2014; Cannon et al. 2015).

A breakdown by student researchers' academic years is provided in Table 3 .

Table 3. Academic Year of Recent Summer and Academic Year (AY) Student Researchers

\begin{tabular}{|l|l|}
\hline AY Research (2013-15) & $\begin{array}{l}\text { Summer Research (2014- } \\
\mathbf{2 0 1 5}\end{array}$ \\
\hline Seniors $32.4 \%$ & \\
\hline Juniors $24.3 \%$ & Juniors $42.1 \%$ \\
\hline Sophomores $32.4 \%$ & Sophomores $44.7 \%$ \\
\hline First Years $10.8 \%$ & First Years $13.2 \%$ \\
\hline 38 Total Students & 37 Total Students \\
\hline
\end{tabular}

\section{Educational Outcomes}

We measure the effectiveness of the program partly through the paths taken by each student in the program after she or he graduates. Additionally, in the last three years, our external assessor has gathered data in the form of anonymous surveys of four groups-students who attended the January workshop, students who observed at Arecibo, faculty involved in UAT, and student alumni (from all years) of the UAT program. The student surveys were adapted from the Survey on Undergraduate Research (SURE; Lopatto 2008), which identifies and measures a number of benefits expected from students' participation in research.

So far, more than 250 students have participated in the program over eight years, with women making up about 40 percent of participants. In the last three years, 30 percent of participants in workshop and on-site observations were Hispanic/Latino students and eight percent were AfricanAmerican students. Participating students are chosen in a variety of ways at their home institutions. Most have taken physics, but there are no specific academic requirements for participation; the open, usually non-competitive opportunities for students to join UAT may enhance the involvement of underrepresented groups. A few participants have even been advanced high school students enrolled in college courses. Many students stay involved over multiple years and work on more than one project, often serving as mentors to their younger colleagues. UAT faculty members have supervised 159 summer research projects and 121 academic-year projects. These have led to 59 presentations at major national conferences (such as the AAS) and countless others at ALFALFA workshops, local conferences, and college research symposia. Many UAT alumni are enrolled in STEM graduate programs, with almost 90 percent pursuing a career in STEM fields (see Table 4).

Table 4. Status of 174 UAT Alumni Through Fall 2015

\begin{tabular}{|c|c|c|c|c|}
\hline \multirow{2}{*}{$\begin{array}{l}\text { Status of } 174 \text { ALFALFA } \\
\text { Alumni }\end{array}$} & \multicolumn{2}{|c|}{ All Alumni } & \multicolumn{2}{|l|}{ Women } \\
\hline & Number & $\%$ & Number & $\%$ \\
\hline Graduate School, any STEM field & 99 & 57 & $37 / 99$ & 37 \\
\hline $\begin{array}{l}\text { Graduate School, physics or } \\
\text { astronomy }\end{array}$ & 63 & 36 & $30 / 63$ & 48 \\
\hline Employed, any STEM field & 43 & 25 & $17 / 43$ & 40 \\
\hline $\begin{array}{l}\text { Graduate, Seeking STEM } \\
\text { employment }\end{array}$ & 8 & 5 & $2 / 8$ & 25 \\
\hline Graduate School, non-STEM & 5 & 3 & $2 / 5$ & 40 \\
\hline Employed, non-STEM & 13 & 8 & $8 / 13$ & 62 \\
\hline $\begin{array}{l}\text { STEM (Graduate school or } \\
\text { employed) }\end{array}$ & 142 & 82 & $54 / 142$ & 38 \\
\hline
\end{tabular}

Results from surveys are overwhelmingly positive. For example, three years of surveys of workshop participants found that a great majority of students (89 percent) were "very satisfied" with the overall experience. Most (81 percent) felt that the workshop was helpful in clarifying their career paths, and 77 percent indicated that their experience at the workshop increased their interest in the STEM fields "a lot." Most students also reported large or very large gains in learning to work collaboratively (83 percent) and in becoming part of a learning community (77 percent). Responses are similar for surveys of on-site Arecibo observations. Students described the experience as "very educational and enjoyable," "incredible," and "amazing."

One student wrote that "one of the most important [aspects] of the experience is the opportunity to actually get to see what having a research life might be like." Another said, "Please continue to make these available for students. They are a great opportunity and are life-changing!" A full 100 percent of these students said they "definitely" planned a career in a STEM field. Surveys of participants in workshops and observation visits have also found near-significant trends toward greater gains in areas such as self-confidence in a scien- 


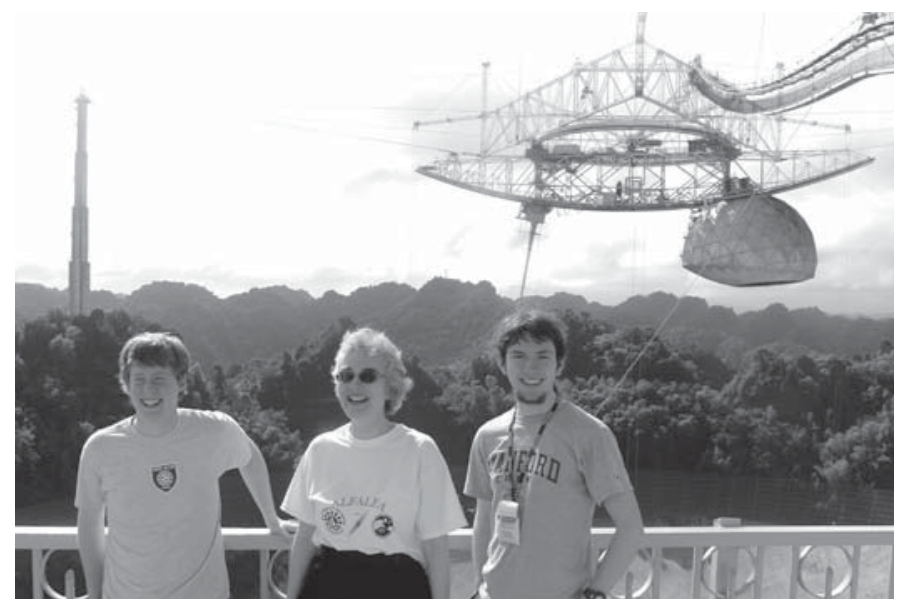

Dr. Rebecca Koopmann (Union College-leader of the UAT) and two of her students Lucas Viani (left, currently at Yale University) and Wyatt Smith (right, currently at Stanford University) are seen here at an overlook point of the "World's Largest Radio Telescope" at Arecibo Observatory. The area of the dish is about the size of 26 football fields and is used by the Undergraduate ALFALFA Team to study the gas content of galaxies that are up to 800 million light years away.

tific setting, for female students, and gains in areas such as, self-confidence in a scientific setting, learning about scientific measurement, and increased interest in STEM fields, for students from underrepresented racial/ethnic groups.

Importantly, UAT alumni report that their experience provided the confidence and connections they needed to make decisions concerning their future lives, with 75 percent reporting that the ALFALFA experience encouraged their interest in research "quite a bit." Specific comments included: "The program gave me more confidence in my ability to succeed as a scientist"; "Presenting my work at the workshop, specifically, was hugely helpful to my academic confidence"; and "It opened a ton of doors to me at a time when I was ready to learn and explore."

Another outcome has been the impact on the professional development of UAT faculty, who might otherwise be isolated at their home institutions. The importance of having professionally engaged teaching faculty who belong to "communities of practice" is well documented. As Etienne Wenger wrote in 1998, “... teachers need to 'represent' their communities of practice in educational settings. This type of lived authenticity brings into the subject matter the concerns, sense of purpose, identification, and emotion of participation. ... The principle suggests that being an active practitioner with an authentic form of participation might be one of the most deeply essential requirements for teaching." (Etienne Wenger 1998).

Specifically, faculty in the UAT report several different advantages to the collaboration. Said one faculty member, "Since I have a very heavy teaching load, only this collaboration is keeping me alive as a research astronomer. It's vitally important." Another said, "I come from a major research institution and am ALFALFA co-lead. It's a long slog to stay engaged at such an intense level for so many years. Being involved in the UAT is very satisfying, because of their enthusiasm and the realization that ALFALFA is making a difference to so many people." Said another participating faculty member, "Our high-performing scholarship students thrive on being challenged and would not have been able to participate in any significant research experience without ALFALFA. All three of my current students plan to attend graduate school."

For many of the UAT institutions with smaller departments, the impact has been even more dramatic. A faculty member from St. Lawrence University summarized the impact this way: "Before ALFALFA, no SLU student had gone on to graduate school in astronomy [since I came here in 1988]. Since engaging with ALFALFA, four students have gone on to graduate school in astronomy. ... It's a fantastic program that has really enriched astronomy at undergraduate institutions." At Hartwick College, physics students had been involved in research only for their senior thesis during the winter or spring of their final semester. Since Hartwick joined ALFALFA, however, many younger students have been involved, and all six who have done ALFALFA summer research projects have gone on to present at national conferences, earn college research prizes, and attend graduate school in a STEM discipline. The spark of collaborative research spread throughout the Department of Physics, and all faculty members now collaborate with freshmen and sophomores regularly.

\section{Lessons Learned}

In looking back at a decade of the UAT, we see a variety of sources of our successes, as well as lessons learned along the way.

It is to our advantage that the physics associated with obtaining information from the atomic hydrogen spectral line is actually quite simple, so that students have an intuitive picture of what the data mean. The fact that we use data from the largest telescope in the world also helps spur interest. During remote observing sessions at our small and often rural campuses, participants report students from classes invited to "stop by" the session can be truly amazed to see their professors and fellow students operating a major telescope an ocean away from where they stand. An additional advantage for us is the sheer amount of data associated with the survey (over 800 observing runs and nearly 5,000 hours of telescope time), hence observing by undergraduates has made a significant contribution toward the completion of the ALFALFA survey and ongoing follow-up projects.

Nonetheless, it is clear that the success of the program hinges more than anything else on the dedication of people in two key positions. The leaders of the ALFALFA survey, especially Martha Haynes at Cornell University, are deeply invested in the UAT aspect of the project, interacting closely with the UAT principal investigators and participating in many of the UAT events. Similarly, the leaders of the UAT, especially Rebecca Koopmann at Union College, devote much of their professional energy to running the program.

A second lesson is the importance of regular communication 


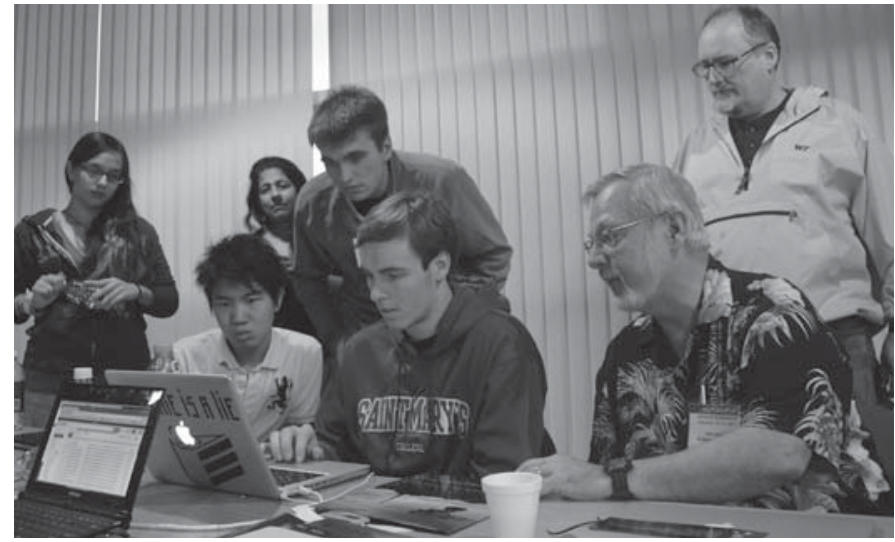

Students and faculty are shown working collaboratively on one of the many "Scavenger Hunts" during the 2013 workshop. The culmination of the work is a presentation of results to the entire group at night. From left to right are Alyssa McElroy (West Texas A\&M University, currently pursuing a Masters at the University of Erlangen, Germany), Long Yan Yung (University of San Francisco, currently pursuing a PhD in astrophysics at Rutgers University), Dr. Aparna Venkatesan (University of San Francisco), Kyle Murray (Hartwick College, currently pursuing a PhD in Astrophysics at the University of Rochester), Blake Tormey and Dr. Ron Olowin (both from St. Mary's College of California), and Dr. David Craig (West Texas A\&M University).

and events to the coherence of the program. Besides the annual workshop at Arecibo, we have monthly teleconferences for all UAT faculty members, a summer research teleconference for faculty and students, and groups that meet regularly for observing and planning to attend conferences. To ease communication among the institutions, we have both a public web site (egg.astro.cornell.edu/alfalfa/ugradteam/ ugradteam.php) and a private Google site that we can all use to upload background information, computer programs, sets of instructions for observing routines, and data-analysis procedures. Having very well-documented and easily accessible information allows participants to build efficiently on previous work.

The strong backbone of infrastructure and dedicated project leaders allows flexibility in how individual UAT faculty members can participate in the program. Faculty can choose when and if to take on summer research students, help with observing runs, and attend workshops. We believe this flexibility has contributed to the longevity of the program.

We continually work to improve the annual January workshop, increasing its efficiency and the impact it has on the faculty and students involved. Several years ago, the workshops were modified to include "advanced sessions," which operate parallel to the more basic sessions aimed at students and faculty traveling to the observatory for the first time. The advanced sessions expand the knowledge of faculty members and advanced students and allow planning future courses of action. We also recently added student presentations of group-project results to the schedule. During the day, teams of students with at least one returning faculty member perform research involving Arecibo data and other astronomical databases and then present their results as a team in the evening. The teams have worked with a greater sense of urgency since the addition of the nightly presentations.

\section{Applying this Model to Other Projects}

The UAT model has been effective in one astronomical survey, but we believe it could be adapted to fit any large scientific collaboration. We have several pieces of advice.

1. At least two core leaders are necessary. One would coordinate activities such as workshops, scientific observations, and participation in national meetings. The other should be a core member of the major research project. This person must recognize the importance of extending undergraduate research beyond his or her home institution and in broadening participation among students from diverse backgrounds. This person should also have a sense of what undergraduates and faculty members with heavy teaching loads are capable of contributing. This person provides the expertise to suggest projects and coordinate the efforts to distribute the work across the collaboration.

2. The background requirements for collaborating faculty members can be very flexible. We identified UAT collaborators through existing personal connections, initially through geographical proximity to Cornell University and participation in the Astronomical Society of New York, a state-wide society for professional astronomers. Geographical proximity is an advantage when funding is limited. The most important qualification of participating faculty is not their scientific specialty, but their willingness to learn and contribute. Our faculty members had a range of expertise.

3. The level and types of participation for collaborating faculty can be very flexible. This allows members to stay in the collaboration through periods of heavy administrative and teaching duties, and responsibilities that preclude extensive travel.

4. The level of knowledge and types of particiation for students are also flexible. Some participate peripherally by helping out at observing sessions or writing some computer programs, while others make significant contributions through summer and/or academic year research projects, many of which serve as "capstone" experiences required for their degrees and lead to refereed publications.

5. Our NSF funding has made possible our transformative workshop and observing experiences at a national observatory, as well as summer research and conference presentations for a large number of students. This has been invaluable for faculty at institutions with limited local resources. With more limited funding, many aspects of the model could still be applied, especially for existing scientific projects, particularly when work can be done remotely via teleconferencing. For example, small local workshops are possible with little funding, and many 


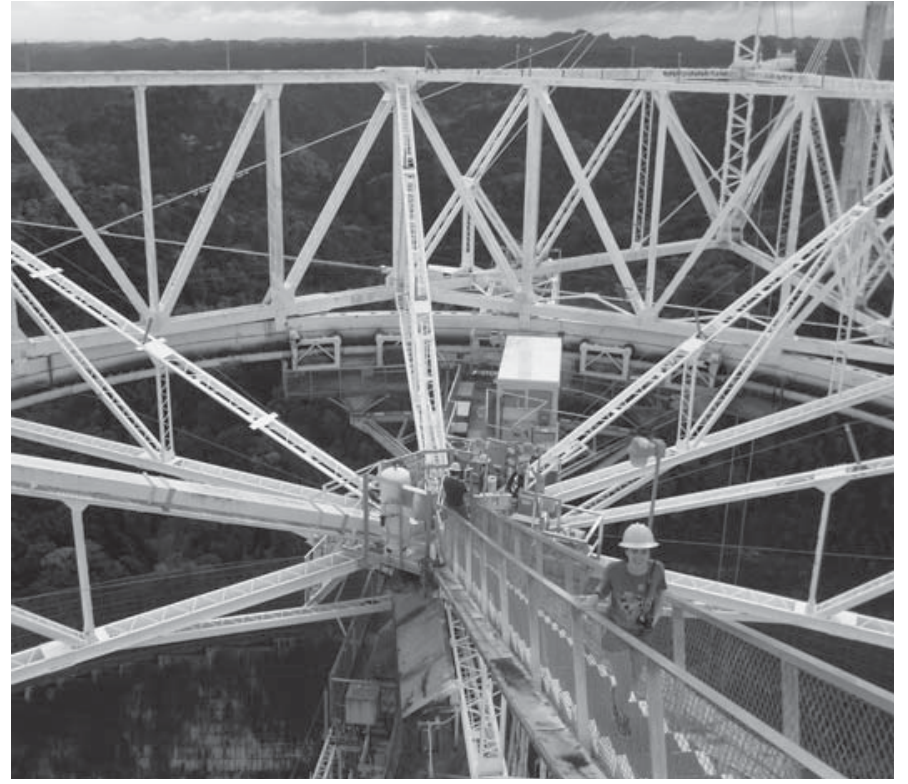

Haley Sharp (University of San Francisco '12) climbs up on the 900-ton platform suspended above the $1000 \mathrm{ft}$. radio dish at the National Astronomy and lonosphere Center (NAIC) in Arecibo, Puerto Rico during the 2012 ALFALFA Workshop. The undergraduate team members were guided by NAIC staff members, who explained the operation of the telescope controls and several of the cameras (receivers) housed inside the Gregorian Dome.

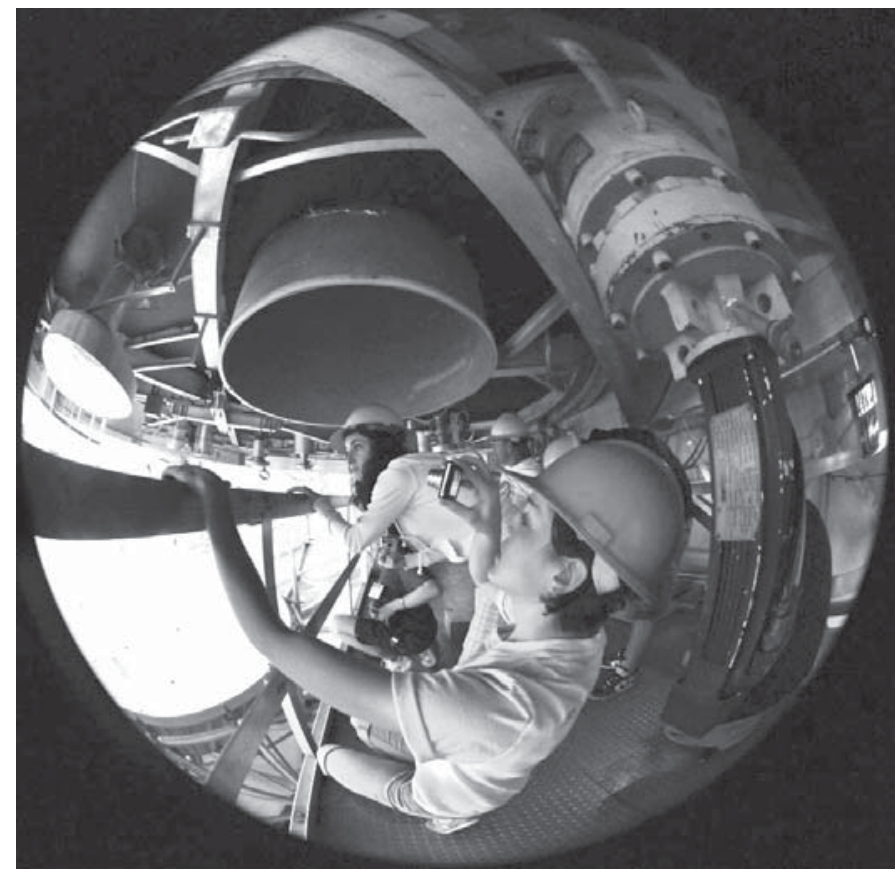

Patti Carroll and Erin O'Malley (background) are seen here during a tour inside the massive Gregorian Dome. The dome is about the size of a six-story building and helps block unwanted radio frequency interference from reaching the receivers ("cameras") inside. Patti recently completed her PhD in astronomy at the University of Washington and Erin is currently a PhD student in astronomy at Dartmouth College. Both are alumni of Siena College and worked under Dr. Rose Finn. small colleges do provide research and travel funding for limited numbers of students.

\section{Final Thoughts}

We emphasize that the effectiveness of our program is bolstered by the recognition that participation by undergraduates can be truly useful to the health of a major long-term research project. In our case, a major example is data collection; although it takes a significant effort to train faculty and students, this has paid off in a project that requires many hours of observing time. In addition, graduate students participate in the UAT through training faculty and undergraduate members and in the process the students gain experience, connections, and confidence that help them in their careers. It also true that many granting agencies require not only strong scientific goals of grantees, but also evidence that supported projects have a broader impact on their fields. The UAT provides a strong, demonstrable impact on science education.

It is also worth noting that members of the project are not strong-armed into being involved with it. The fact that no one feels pressured to participate beyond what works for him or her creates a healthy environment in which students can learn the excitement and value of collaboration, along with specific information and technical skills.

In conclusion, we feel that we have found a meaningful way for undergraduates, even at small isolated institutions, to be involved in major long-term research-a way that makes them part of the academic community, helps them learn useful skills, and allows them to see for themselves the Big Picture behind Big Science.

\section{Acknowledgements}

The UAT gratefully acknowledges the efforts of the entire ALFALFA team for assistance with the survey and NAIC staff members for their help with workshops and observing runs. The UAT is supported by NSF grants AST0724918/0902211, AST-0725267/0903394, AST-0725380, and AST-1211005. The ALFALFA survey at Cornell is supported by NSF AST-0607007 and AST1107390 and by the Brinson Foundation.

* Legacy Science Projects are large coherent projects that have a general and lasting importance to the broad astronomical community. A key element of such programs is to produce data products that maximize scientific impact and are invaluable for multi-wavelength data mining.

\section{References}

Committee for a Decadal Survey of Astronomy and Astrophysics, National Research Council of the National Academies. 2010. New Worlds, New Horizons in Astronomy and Astrophysics. Washington, D.C.: National Academies Press.

Bernstein-Cooper, Elijah, Z., John M. Cannon, Edward C. Elson, Steven R. Warren, Jayaram Chengular, Evan D. Skillman, Elizabeth A. K. Adams, Alberto D. Bolatto, Riccardo Giovanelli, Martha P. Haynes, Kristen B. W. 
McQuinn, Stephen A. Pardy, Katherine L. Rhode, and John J. Salzer. 2014. "ALFALFA Discovery of the Nearby Gas-rich Dwarf Galaxy Leo P. V. Neutral Gas Dynamics and Kinematics." The Astronomical Journal 148 (2): 35. doi: 10.1088/0004-6256/148/2/35.

Cannon, John M., Riccardo Giovanelli, Martha P. Haynes, Steven Janowiecki, Angela Parker, John J. Salzer, Elizabeth A.K. Adams, Eric Engstrom, Shan Huang, Kristen B. W. McQuinn, Jürgen Ott, Amélie Saintonge, Evan D. Skillman, John Allan, Grace Erny, Palmer Fliss, and AnnaLeigh Smith. 2011. "The Survey of H I in Extremely Low-mass Dwarfs (SHIELD)." The Astrophysical Journal Letters 739 (1): L22. doi: 10.1088/2041-8205/739/1/122.

Cannon, John M., Charlotte P. Martinkus, Lukas Leisman, Martha P. Haynes,Elizabeth A. K. Adams, Riccardo Giovanelli, Gregory Hallenbeck, Steven Janowiecki, Micahel Jones, Gyula I. G. Józsa, Gyula, Rebecca A. Koopmann, Nathan Nichols, Emmanouil Papastergis, Katherine L. Rhode, John J. Salzer, and Parker Troischt. 2015. "The ALFALFA 'Almost Darks' Campaign: Pilot VLA HI Observations of Five High Mass-to-Light Ratio Systems." The Astronomical Journal 149 (2): 72. doi: 10.1088/0004$6256 / 149 / 2 / 72$.

Giovanelli, Riccardo, Martha P. Haynes, Brian R. Kent, Philip Perillat, Barbara Catinella, G. Lyle Hoffman, Emmanuel Momjian, Jessica L. Rosenberg, Amelie Saintonge, Kristine Spekkens, Sabrina Stierwalt, Noah Brosch, Karen L. Masters, Christopher M. Springob, Igor D. Karachentsev, Valentina E. Karachentseva, Rebecca A. Koopmann, Erik Muller, Wim van Driel, and Liese van Zee. 2005. "The Arecibo Legacy Fast ALFA Survey. II. Results of Precursor Observations." The Astronomical Journal 130 (6): 2613-2624. doi: $10.1086 / 497432$.

Kuh, George D. 2008. High-Impact Educational Practices: What They Are, Who Has Access to Them, and Why They Matter. Washington, DC: Association of American Colleges and Universities.

Lopatto, David. 2008. "Exploring the Benefits of Undergraduate Research: The SURE Survey." In Creating Effective Undergraduate Research Programs in Science, edited by Roman Taraban and Richard L. Blanton, NY: Teacher's College Press, 112.

Martin, Michael O., Ina V. S. Mullis, Pierre Foy, and Gabrielle M. Stanco. 2012. TIMSS 2011 International Results in Science. Chestnut Hill, MA: TIMMS and PIRLS International Study Center, Boston College.

Mullis, Ina V.S., Michael O. Martin, David F. Robitaille, and Pierre Foy. 2009. TIMSS Advanced 2008 International Report: Findings from IEA's Study of Achievement in Advanced Mathematics and Physics in the Final Year of Secondary School. Chestnut Hill, MA: TIMSS and PIRLS International Study Center, Boston College.

Rowlett, Roger S., Linda Blockus, and Susan Larson. 2012. Characteristics of Excellence in Undergraduate Research. Nancy Hensel (Ed). Washington, D.C.: Council on Undergraduate Research.

York, Donald G., SDSS Collaboration, et al. 2000. "The Sloan Digital Sky Survey: Technical Summary." The Astronomical Journal 120: 1579. doi: 10.1036/1097-8542.802010.

Wenger, Etienne. 1998. Communities of Practice: Learning, Meaning and Identity. Cambridge: Cambridge University Press, 276-277.

\section{Parker Troischt}

Hartwick College, troischtp@hartwick.edu

Parker W. Troischt is an associate professor of physics at Hartwick College, where he teaches astronomy, astrophysics, and courses across the undergraduate physics curriculum. His research interests include extragalactic astronomy, general relativity, and cosmology. He earned a BA in physics from SUNY Geneseo, a PhD in astrophysics from the University of North Carolina at Chapel Hill, and was a visiting researcher at the Canadian Institute of Theoretical Astrophysics in Toronto, Ontario.

Rebecca A. Koopmann is professor and chair of the Department of Physics \& Astronomy at Union College and principal investigator of the Undergraduate ALFALFA Team's National Science Foundation grant. She teaches a variety of courses in physics and astronomy. Her research interests include galaxy evolution in group and cluster environments. She earned her BS in physics at Union College and her PhD in astronomy at Yale University. She has held visiting appointments in the Department of Astronomy at Cornell University and at the National Astronomy and Ionosphere Center.

Aileen O'Donoghue is an associate professor of physics at St. Lawrence University, where she teaches introductory and advanced physics courses and labs, as well as courses on astronomy and global climate for non-science majors. She has studied radio galaxies in rich clusters of galaxies with the Very Large Array radio telescope and with the ALFALFA team at the Arecibo Observatory. She has also conducted observations and contributed to projects in stellar spectroscopy as a visiting scientist with the Vatican Observatory Research Group. She has an AAS from Colorado Mountain College, a BS from Fort Lewis College in Durango, Colorado, and MS and PhD degrees from the New Mexico Institute of Mining and Technology.

Mary Crone Odekon is chair of the Department of Physics at Skidmore College. She teaches courses across the undergraduate physics curriculum and has published on various aspects of galaxy formation and evolution. She has a BS in physics from The College of William and Mary and a PhD in physics from the University of Michigan. She also has worked at the Harvard-Smithsonian Center for Astrophysics and the University of Pittsburgh.

Martha P. Haynes is Goldwin Smith Professor of Astronomy at Cornell University and co-principal investigator of the ALFALFA survey. At Cornell, she teaches both graduate and undergraduate courses on extragalactic astronomy, and her research focuses on the study of nearby galaxy populations and their use as cosmological probes. She is a member of the National Academy of Sciences and a fellow of the American Academy of Sciences and the American Association for the Advancement of Science. In 1989 she was awarded the Henry Draper Medal for her work on the three-dimensional distribution of galaxies in the local universe. She received her $B A$ in physics with special honors in astronomy from Wellesley College and her PhD in astronomy from Indiana University. Before joining the Cornell faculty, she was a staff member at the National Astronomy and Ionosphere Center and the National Radio Astronomy Observatory.

doi: $10.18833 /$ curq/36/4/7 